(c) The Author(s), 2021. Published by Cambridge University Press on behalf of The Nutrition Society. This is an Open Access article, distributed under the terms of the Creative Commons Attribution licence (http://creativecommons.org/licenses/by/4.0/), which permits unrestricted re-use, distribution, and reproduction in any medium, provided the original work is properly cited.

\title{
Estimation of sodium and potassium intakes assessed by two 24-hour urine collections in a city of Indonesia
}

\author{
Dianis Wulan Sari ${ }^{1,2 *}$, Maiko Noguchi-Watanabe ${ }^{1}$, Satoshi Sasaki ${ }^{3}$, Junaiti Sahar ${ }^{4}$ and \\ Noriko Yamamoto-Mitani ${ }^{1}$ \\ ${ }^{1}$ Department of Gerontological Home Care and Long-Term Care Nursing, Division of Health Sciences and Nursing, Graduate \\ School of Medicine, The University of Tokyo, 7-3-1 Hongo, Bunkyo-ku, Tokyo 113-0033, Japan \\ ${ }^{2}$ Department of Community and Gerontological Nursing, Faculty of Nursing, Universitas Airlangga. Jln. Mulyorejo, East Java \\ 60115, Surabaya, Indonesia \\ ${ }^{3}$ Department of Social and Preventive Epidemiology, School of Public Health, The University of Tokyo, 7-3-1 Hongo, Bunkyo-ku, \\ Tokyo 113-0033, Japan \\ ${ }^{4}$ Faculty of Nursing, Universitas Indonesia, Jln. Prof. Dr. Bahder Djohan, West Java 16424, Depok, Indonesia
}

(Submitted 28 May 2020 - Final revision received 29 December 2020 - Accepted 15 January 2021 - First published online 26 January 2021)

\section{Abstract}

Intakes of excess $\mathrm{Na}$ and insufficient $\mathrm{K}$ are two major contributors of heart diseases and stroke development. However, no precise study has previously been carried out on $\mathrm{Na}$ and $\mathrm{K}$ intakes among Indonesian adults. The present study aimed to estimate the $\mathrm{Na}$ and $\mathrm{K}$ intakes using two consecutive 24-h urine collections. Participants were community-dwelling adults aged between 20 and 96 years, randomly selected from a pool of resident registration numbers. Of the 506 participants, 479 (240 men and 239 women) completed urine collections. The mean Na excretion was 102.8 and $100.6 \mathrm{mmol} / \mathrm{d}$, while the mean $\mathrm{K}$ excretion was 25.0 and $23.4 \mathrm{mmol} / \mathrm{d}$ for men and women, respectively. Na and $\mathrm{K}$ excretions were higher in participants with a higher BMI. A higher K excretion was associated only with younger age. More than $80 \%$ of the participants consumed more than $5 \mathrm{~g} / \mathrm{d}$ of salt (the upper limit recommended by the Indonesian government), whereas none of them consumed more than $3510 \mathrm{mg} / \mathrm{d}$ of $\mathrm{K}$ (the lower limit). The high Na and low K intakes, especially high Na among participants with high BMI, should be considered when future intervention programmes are planned in this country.

Key words: 24-Hour urine: Intake: Sodium: Potassium: Urine excretion

In Indonesia, the common non-communicable diseases that lead to death are stroke, heart disease and cancer ${ }^{(1)}$. Excess Na intake and insufficient $\mathrm{K}$ intake have been generally reported as factors associated with the development of stroke and heart disease $\mathrm{e}^{(2-5)}$ However, consensus has not been reached regarding the association between $\mathrm{Na}$ intake, blood pressure and heart disease $\mathrm{e}^{(5-8)}$ The findings of previous studies have not been consistent with regard to the association between high and low $\mathrm{Na}$ intake and mortality related to heart disease ${ }^{(7-13)}$. Although the definitions of 'high' and 'low' for $\mathrm{Na}$ intake are unclear ${ }^{(8)}$, the average daily consumption of $\mathrm{Na}$ is between 3.0 and $6.0 \mathrm{~g} / \mathrm{d}$ globally ${ }^{(14-16)}$, and many countries and regions have instituted salt reduction programmes.

Before intervention programmes for reducing $\mathrm{Na}$ and increasing $\mathrm{K}$ intakes are discussed, considered or planned, actual intakes of which reliability is high enough should be referred.
Nationwide studies including those conducted in the UK, Japan, Spain, Italy, Turkey and Slovenia ${ }^{(17-22)}$ have reported estimations of $\mathrm{Na}$ and $\mathrm{K}$ intakes based on 24-h urine to evaluate the progress of salt reduction programmes ${ }^{(17-25)}$. However, thus far, there has been no nationwide survey of $\mathrm{Na}$ and $\mathrm{K}$ intakes in the Indonesian population. Hitherto, only two studies have evaluated $\mathrm{Na}$ and $\mathrm{K}$ intakes among Indonesians, both with methodological limitations. One study used 24-h dietary recall ${ }^{(26)}$, and the other study used a 24-h urinary analysis in a small and single-sex sample ${ }^{(27,28)}$

Several methods have been used to evaluate $\mathrm{Na}$ and $\mathrm{K}$ intakes, including food consumption questionnaires ${ }^{(29)}$, spot urine collection $^{(30)}$ and 24-h urine collection ${ }^{(18,20,31,32)}$. Because $86 \%$ of $\mathrm{Na}$ and $77 \%$ of $\mathrm{K}$ consumed through the diet are excreted in the urine over $24 \mathrm{~h}^{(33)}$, the 24 -h urine collection is considered the 'gold standard' method for $\mathrm{Na}$ and $\mathrm{K}$ intake measurements, in

Abbreviation: PAL, physical activity level.

* Corresponding author: Dianis Wulan Sari, email dianis-wulan@umin.ac.jp 
individuals and populations ${ }^{(34)}$. Since it is necessary to evaluate $\mathrm{Na}$ and $\mathrm{K}$ intakes in a representative sample of individuals, a community-based approach may be appropriate for Indonesian people, especially those living in sub-urban and rural areas ${ }^{(35)}$.

The present study aimed to precisely determine the $\mathrm{Na}$ and $\mathrm{K}$ intakes of people living in a city of Indonesia by evaluating in two consecutive 24-h urine collections.

\section{Methods}

\section{Study design and study area}

This cross-sectional descriptive correlational study was conducted in a city of East Java, Indonesia. The prevalence of hypertension, stroke and heart disease in this province was higher than the national prevalence of these diseases ${ }^{(35,36)}$. The present study was conducted in the city of Nganjuk, as it is representative of a sub-urban area and is a flat, non-coastal city in Indonesia. Data collection for this survey was carried out by home visits. To increase the reliability and the convenience in collecting data to facilitate the analyses of the urine, only one city was selected for the study.

\section{Study participants and sampling methods}

The participants were community-dwelling young (aged $20-59$ years) and older adults (aged $\geq 60$ years). The age group cut-offs were based on the standard values set by the Indonesian government ${ }^{(37)}$. The exclusion criteria were as follows: unable to provide informed consent, difficulties with memory or communication, following a diet prescribed by a doctor or a dietitian at the time of the study or within 1 year prior to the study, fasting, severe diseases (i.e. kidney failure, total paralysis and liver disease) and presence of other conditions could cause difficulties in the 24-h urine collection. We obtained the residents' data from the city office. In randomising, the groups were classified by age group and sex.

The main investigator used a computer-based random number generator, to select the sample from a pool of the residents' identity card numbers. We calculated the sample size based on the study population for $\mathrm{Na}$ levels ${ }^{(38)}$. A previous study recommended a minimum sample size of 120 individuals per sex stratum to detect an approximately $1 \mathrm{~g}$ reduction in salt intake over time, based on 24-h urinary $\mathrm{Na}$ excretion, with a SD of $75 \mathrm{mmol} / \mathrm{d}$ $(\alpha=0 \cdot 05 \text {, power }=0 \cdot 80)^{(38)}$. To compensate for possible attrition (e.g. nonparticipation or implausible values), which may have accounted for as high as $10 \%$ of participants, up to 132 people per group stratum (in total 528) were invited to participate.

The present study was conducted according to the guidelines laid down in the Declaration of Helsinki and all procedures involving human subjects/patients were approved by the ethical committee of The University of Tokyo (approval number, 12015). Written informed consent was obtained from all participants. All the participants whose data were collected received an incentive at the end of the data collection.

\section{Data collection}

All data were collected between November 2018 and September 2019. The data collection process required $4 \mathrm{~d}$ per participant
(Fig. 1). On the first day, the investigator visited the resident's home and provided the information about the study. We confirmed the inclusion and exclusion criteria of the participants while providing an explanation of the study. People who agreed to participate provided written consent. Next, the data regarding the participant's characteristics was collected, and a physical examination was conducted. We then provided instructions on the 24-h urine collection process and on how to complete the self-recorded 24-h urine collection sheet. All equipment was provided by the researcher. On the second to fourth days, the participants began the urine collection at their home. The adverse event in urine collection and other measurement was confirmed on the fourth day.

Participants' characteristics. The section in the questionnaire on participants' characteristics was developed using the STEPS instrument ${ }^{(39)}$ and used to obtain data on age, sex, education level, medical history, occupation, current drug consumption, tobacco use and alcohol consumption. In the older adult population, activities of daily living were measured using the Barthel Index ${ }^{(40)}$. The Mini-Cog ${ }^{\Theta(41)}$, which is used mainly in the older population, was used to measure the cognitive status. We measured activity patterns using the physical activity levels (PAL) from the long version of the International Physical Activity Questionnaire $^{(42)}$. We estimated the PAL value by summing the result of the time spent on each of a range of activities with various exercise intensities and metabolic equivalent of task values for each activity ${ }^{(43)}$. The International Physical Activity Questionnaire has been validated for use in many countries and translated into many languages ${ }^{(44)}$.

24- $h$ Urine collection. We estimated daily $\mathrm{Na}$ and $\mathrm{K}$ intakes based on the 24-h urinary excretion. The 24-h urine collection was performed on two consecutive days, using a protocol based on the WHO/Pan American Health Organization report and based on a previous study conducted in $\operatorname{Japan}^{(18,38)}$. The urine collection start time (around 05.00 hours) was adjusted to the Indonesian culture for the morning prayer. For urine collection day 1 , the participants discarded the first morning urine at around 05.00 hours and, thereafter, all the urine samples were collected. Day 1 collection was completed the next day at the same time (05.00 hours). For day 2, at 05.00 hours, the participants collected the last specimen of day 1 ; therefore, they did not need to discard the urine to start day 2. The participants needed to change only the bottle for day 2 collection after 05.00 hours. However, we made it flexible for participants to start urine collection between 04.45 and 05.30 hours. If the participant changed the start time, then they would finish at the corresponding end time. We distributed four 1-litre bottles/d. The participants were asked to carry a plastic bottle when they went out and to keep the bottle away from sunlight and cold places. They had separate bottles 'for home use' and 'for outside the home'. Disposable plastic and paper cups were used for easy urine collection, before the urine was poured into the bottle.

We collected the urine from the participants' homes at approximately $05.15-05.30$ hours to ensure the acquisition of urine samples. We asked the participants to repeat the urine collection process when the following conditions occurred: (1) the 


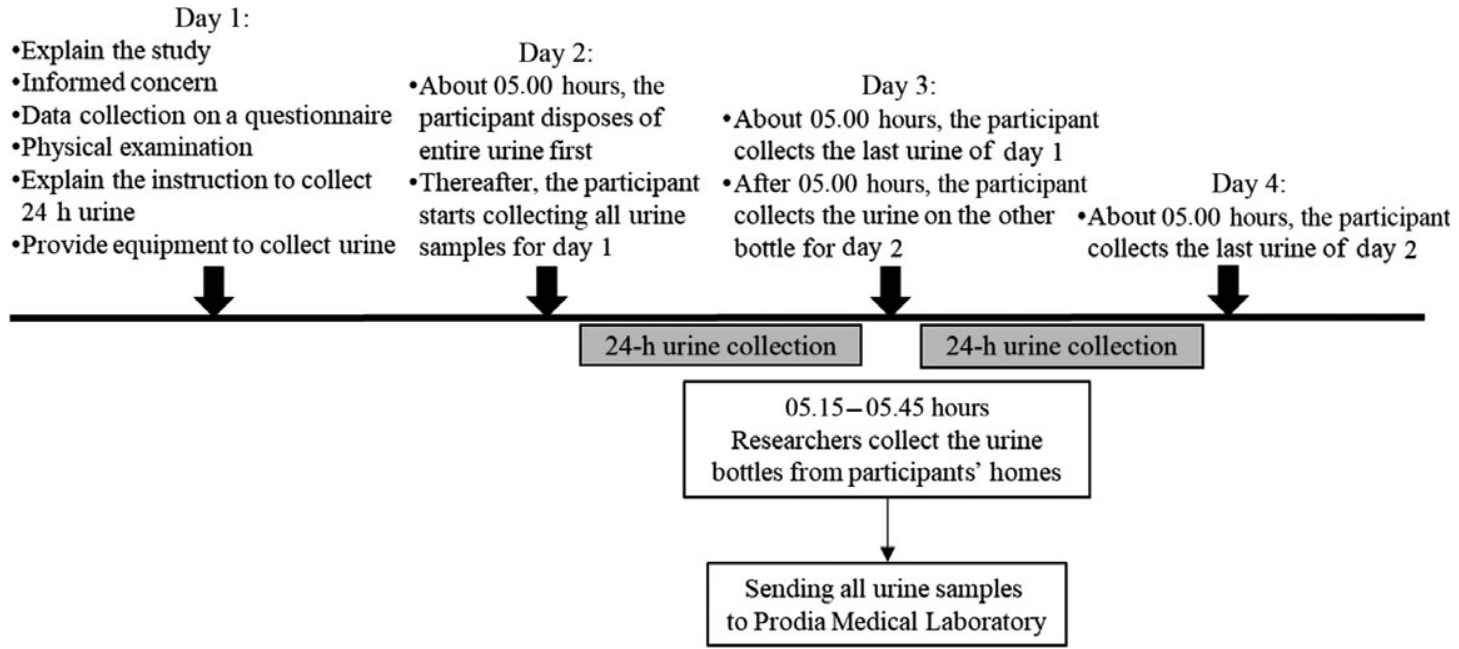

Fig. 1. Process of data collection.

duration of urine collection exceeded $24 \mathrm{~h}$ and $30 \mathrm{~min}$, and (2) participants reported that they had forgotten to collect the urine more than once or were 'missing more than a few drops and could not estimate the amount'. A previous study that used participants' self-reporting of missed urine collection mentioned that this method is reliable for measuring completeness of 24-h urine in large population-based biomarker studies ${ }^{(45)}$. Based on previous population surveys, it is preferable to ask participants to repeat the collection if it is potentially incomplete, to ensure complete and accurately timed 24-h urine collection. Such methods were used in the INTERSALT and INTERMAP studies $^{(46,47)}$.

We provided a self-reporting sheet, for the participants to record the start and finish times, as well as the estimated frequency and volume of urine that they forgot or failed to collect. We included the estimated amount along with the actual volume of urine collected. The overall total amount of urine was calculated by Prodia Medical Laboratory, after adjusting for collection times based on the collection records. This method was validated using the para-aminobenzoic acid check method ${ }^{(48)}$.

The Prodia Medical Laboratory used the ISE indirect $\mathrm{Na}-\mathrm{K}-\mathrm{Cl}$ for Gen.2; the ISE module of the Roche/Hitachi cobas c system (Roche Diagnostic) for the quantitative determination of $\mathrm{Na}$ and $\mathrm{K}$ in urine using ion-selective electrodes. CREP2 creatinine plus ver.2 was used (in vitro test (enzyme test)) for the quantitative determination of creatinine concentration in urine on the cobas c 111 system (Roche Diagnostic). Na and K excretions and the $\mathrm{Na}: \mathrm{K}$ ratio were calculated as follows:

Total 24-h urine excretion $(\mathrm{mmol} / \mathrm{d})=$ adjusted volume of $24-\mathrm{h}$ urine $(\mathrm{ml} / \mathrm{d}) \times$ concentration $(\mathrm{mmol} / \mathrm{ml})$.

Note: $1 \mathrm{mmol}$ of $\mathrm{Na}$ is equal to approximately $58.5 \mathrm{mg}$ of $\mathrm{NaCl}$ (salt)

$1 \mathrm{mmol}$ of $\mathrm{K}$ is equal to approximately $39 \cdot 1 \mathrm{mg}$ of $\mathrm{K}$

$$
\mathrm{Na}: \mathrm{K} \text { ratio }=\frac{\mathrm{Na}(m g / d)}{K(m g / d)}
$$

Physical examination and environment. Blood pressure was measured using the clinical blood pressure technique ${ }^{(49,50)}$. The measurement was conducted three times using electronic monitors (Omron HEM-7130 with cuff from Omron HEM-CR24 by Omron Healthcare Co. Ltd.) as validated by Takahashi et $a l .{ }^{(51)}$. The protocol for blood pressure measurement was based on the British Hypertension Society guidelines and the WHO/Pan American Health Organization. Participants rested for 1 min between each of the readings ${ }^{(38,52,53)}$. The heart rate was also measured three times. The body weight and height were used to calculate BMI. Body weight $(\mathrm{kg})$ was measured using a portable digital scale (Omron HN-286 by Omron Healthcare Co. Ltd.) in units of $100 \mathrm{~g}$ and capacity $180 \mathrm{~kg}$. Body height $(\mathrm{cm})$ was measured using a portable stadiometer to the nearest $0 \cdot 1 \mathrm{~cm}$ and capacity $2 \mathrm{~m}$. The weight scale was calibrated daily before each use.

Temperature and humidity have an effect on 24-h urine excretion. However, it was difficult to measure the climate for the $24 \mathrm{~h}$ of the individual collections. Therefore, we decided to collect data on temperature and humidity using a thermometer and a hygrometer (Citizen THD501; Citizen System Co. Ltd.), respectively, once daily at 10.00 hours in randomly selected homes in the community area. Almost all the homes of the participants did not have air conditioning.

All the measurements were made according to a standardised protocol by well-trained researchers.

\section{Statistical analysis}

The completeness of the 24-h urine collection was confirmed before the analysis. First, we examined the completeness of the urine collection using two equations. Day 1 ( $n$ 484) used Joossens et al.'s equations ${ }^{(48,54)}$. Joossens et al. used a value of $<0.6$ (urinary creatinine $(\mathrm{mmol} / \mathrm{d}) \times 113) /(21 \times$ body weight $(\mathrm{kg})$ ). If the ratio of urinary creatinine $(\mathrm{mg} / \mathrm{d})$ to body weight (kg) calculated for collection was $<60 \%$ or $>140 \%$ of the expected value, then that urine sample was excluded from the analysis. Therefore, ninety-nine urine samples (i.e. $<60 \%, 84$ samples and $>140 \%, 15$ samples) were excluded from the day 1 collection. The creatinine value was not available for the day 2 urine collection. Therefore, for the day 2 collection ( $n$ 482), we used the equations based on the urine volume 
and self-reported urine collection. Samples with $<250 \mathrm{ml}$ total volume, long $(>26-\mathrm{h})$ or short $(<22-\mathrm{h})$ urine collection period or unknown amount of urine loss were excluded. The combination of urine volume and the self-reported method has been verified by para-aminobenzoic acid recovery in an earlier study ${ }^{(55)}$. We excluded seven samples from day 2.

Two types of urinalyses were performed. The first was categorised by sex using the data collected from as many participants as possible (successful samples from day 1 or 2, or both, collections). When both samples were considered complete, the mean value was used; when only one collection was considered complete, its value was considered the representative one. This decision was made based on the results of previous studies and using concordance analyses (Bland-Altman, linear regression, Cohen's $\kappa$ and Spearman analyses $)^{(18,56)}$. The first analysis included 479 participants ( 240 men and 239 women). In the second type of urinalysis, the distribution of the habitual $\mathrm{Na}$ and $\mathrm{K}$ excretions was calculated only for participants with two successful 24-h urine collections. The second analysis included 380 participants (204 men and 176 women).

We analysed the data for men and women separately due to the different urine excretions between sexes caused by factors such as dietary pattern, age, BMI and $\mathrm{PAL}^{(18,19,57)}$. The difference in the participants' characteristics was analysed using the Student's $t$ test and $\chi^{2}$ test. We then calculated the $\mathrm{Cr}$ ratio, as of the observed to the expected $\mathrm{Cr}$ excretion, as described by Joossens et al. ${ }^{(58)}$. $\mathrm{Na}$ and $\mathrm{K}$ excretions were then calculated as the excretion of the electrolytes per $1 \mathrm{~g}$ excretion of creatinine. Additionally, the $\mathrm{Na}$ and $\mathrm{K}$ excretions ratio was calculated and expressed as $\mathrm{mg} / \mathrm{d}$.

A multivariable linear regression model was used to examine the association between age, BMI, and PAL and urine excretion. To compare the effect of each covariate quantitatively, we used standardised partial regression coefficients. The distribution of habitual intake of $\mathrm{Na}$ and $\mathrm{K}$ in the analysed population was simulated using HabitDist software version 1.2 based on the bestpower method ${ }^{(59,60)}$ to account for day-to-day variation ${ }^{(61)}$. This programme estimated the means and standard deviations and distribution (10th, 25th, 50th, 75th and 90th percentiles) of the usual $\mathrm{Na}$ and $\mathrm{K}$ excretions (as well as the proportion above or below the defined cut-off values). For the cut-off values, we used the WHO and Indonesian government recommendations for decreasing salt and improving $\mathrm{K}$ intake ${ }^{(62-64)}$. Based on the estimation reported in a previous study that $86 \%$ of $\mathrm{Na}$ and $77 \%$ of $\mathrm{K}$ consumed orally ware excreted into the urine ${ }^{(33)}$, the intake recommendation was adjusted by multiplication with 0.86 for $\mathrm{Na}$ and 0.77 for $\mathrm{K}^{(59,61)}$.

Additionally, we analysed the association between the environment and urine excretion using the Student's $t$ test. All analyses were performed using SPSS version 26 (IBM). $P<0.05$ was considered to be statistically significant.

\section{Results}

We recruited 528 people, and twenty-two people refused to participate in the present study; finally, 506 individuals completed the questionnaire. Of these, 484 took part in the 24-h urine

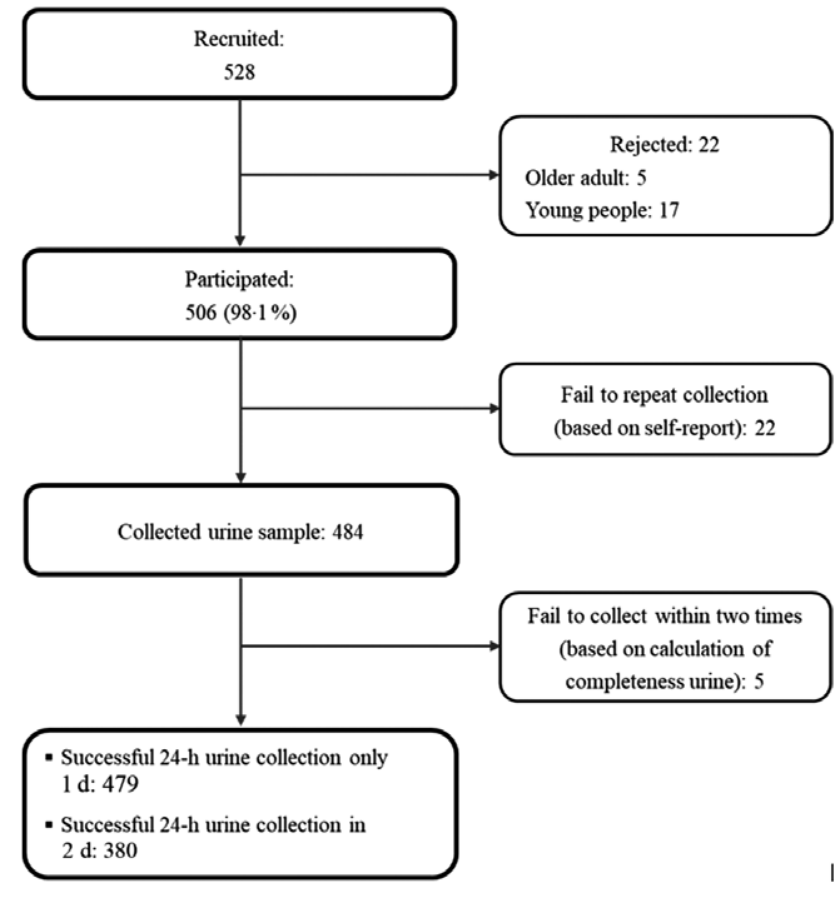

Fig. 2. Flow chart of the study participants.

collection (Fig. 2). Participants' characteristics are summarised in Table 1. We included 240 men and 239 women with a mean age of 56.5 years. Among all participants, $36.7 \%$ were diagnosed with a non-communicable disease, with the prevalence of hypertension in men and women being 24.6 and $34.3 \%$, respectively. In addition, the mean systolic blood pressure and diastolic blood pressure were 139 and $87.4 \mathrm{mmHg}$, respectively. Moreover, the mean BMI was $22.3 \mathrm{~kg} / \mathrm{m}^{2}$, with significant differences observed between men and women participants.

Table 2 showed the result of concordance analysis for day 1 and 2 urine excretions. The mean difference among the $2 \mathrm{~d}$ collection of $\mathrm{Na}$ and $\mathrm{K}$ was $3.05(95 \% \mathrm{CI}-0.96,7 \cdot 07)$ and $0.78(95 \%$ CI $0.05,1 \cdot 5)$, respectively. Despite this, the limits of agreement of $\mathrm{Na}$ and $\mathrm{K}$ were -75 to 81 and -13.3 to $14 \cdot 9$, respectively. From the Spearman analysis, the $r$ ( $P$ value) of $\mathrm{Na}$ and $\mathrm{K}$ for the $2 \mathrm{~d}$ collection was $0.63(<0.001)$ and $0.75(<0.001)$, respectively. The $\kappa$ tests for the Na measurements were $0 \cdot 34$, which represented a fair strength of agreement, while K measurements were $0 \cdot 48$, which represented a moderate strength of agreement.

Data on the excretion of $\mathrm{Na}$ and $\mathrm{K}$ are shown in Table 3 . The mean values for $\mathrm{Na}$ and $\mathrm{K}$ excretions were 102.8 and $25 \mathrm{mmol} / \mathrm{d}$ in men and 100.6 and $23.4 \mathrm{mmol} / \mathrm{d}$ in women, respectively. $\mathrm{Na}$ and $\mathrm{K}$ excretion results by age, BMI and PAL are summarised in Table 4. Mean values of $\mathrm{Na}$ and $\mathrm{K}$ excretions were higher in younger participants, those with higher BMI and those with higher PAL. The Na:K ratios in both men and women were also higher in younger participants and in those with a higher BMI. In men, the Na:K ratio was higher in those with lower PAL, whereas in women the Na:K ratio was higher in those with a higher PAL.

Table 5 shows the results of the multivariate linear regression analysis. Age was significantly associated with a lower Na excretion in women but not in men. For both sexes, the BMI was significantly associated with a higher Na excretion and the BMI and 
Table 1. Characteristics of the study participants

(Mean values and standard deviations; numbers and percentages)

\begin{tabular}{|c|c|c|c|c|c|c|c|}
\hline & \multicolumn{2}{|c|}{ Total (n 479) } & \multicolumn{2}{|c|}{ Men (n 240) } & \multicolumn{2}{|c|}{ Women (n 239) } & \multirow[b]{2}{*}{$P^{\star}$} \\
\hline & Mean/n & $\mathrm{sD} / \%$ & Mean $/ n$ & $\mathrm{SD} / \%$ & Mean/n & $\mathrm{SD} / \%$ & \\
\hline Age (years) & $56 \cdot 5$ & $14 \cdot 7$ & $57 \cdot 0$ & $14 \cdot 8$ & $56 \cdot 0$ & $14 \cdot 6$ & 0.49 \\
\hline Completed secondary school (yes) & 345 & $72 \cdot 0$ & 186 & 77.5 & 159 & 66.5 & 0.007 \\
\hline Married & 374 & $78 \cdot 1$ & 204 & $85 \cdot 0$ & 170 & $71 \cdot 1$ & $<0.001$ \\
\hline Occupation (current) & & & & & & & $<0.001$ \\
\hline Employee & 48 & $10 \cdot 0$ & 32 & $13 \cdot 3$ & 16 & 6.7 & \\
\hline Trade & 81 & $16 \cdot 9$ & 55 & $22 \cdot 9$ & 26 & $10 \cdot 9$ & \\
\hline Farmer & 152 & $31 \cdot 7$ & 120 & $50 \cdot 0$ & 32 & $13 \cdot 4$ & \\
\hline Housewife & 139 & $29 \cdot 0$ & 0 & 0 & 139 & $58 \cdot 2$ & \\
\hline Others & 17 & 3.5 & 12 & $5 \cdot 0$ & 5 & $2 \cdot 1$ & \\
\hline Unemployed (unable to work) & 42 & $8 \cdot 8$ & 21 & $8 \cdot 8$ & 21 & $8 \cdot 8$ & \\
\hline Diagnosed have NCD (yes)† & 176 & $36 \cdot 7$ & 79 & 32.9 & 97 & $40 \cdot 6$ & 0.08 \\
\hline Having multiple NCD (yes)† & 14 & 2.5 & 7 & 2.9 & 7 & 2.9 & 0.99 \\
\hline \multicolumn{8}{|l|}{ The primary NCD $†$} \\
\hline Do not know/do not have a disease & 303 & $63 \cdot 3$ & 161 & $67 \cdot 1$ & 142 & $59 \cdot 4$ & 0.10 \\
\hline Hypertension & 141 & $29 \cdot 4$ & 59 & $24 \cdot 6$ & 82 & $34 \cdot 3$ & 0.03 \\
\hline Diabetes & 7 & 1.5 & 3 & $1 \cdot 3$ & 4 & 1.7 & 0.50 \\
\hline Cardiovascular & 5 & 1.0 & 4 & $1 \cdot 7$ & 1 & 0.4 & 0.37 \\
\hline Cancer & 1 & 0.2 & 0 & 0.0 & 1 & 0.4 & 1.00 \\
\hline Urinary tract stone & 1 & 0.2 & 1 & 0.4 & 0 & 0.0 & 1.00 \\
\hline Chronic gastritis & 1 & 0.2 & 0 & 0.0 & 1 & 0.4 & 1.00 \\
\hline Hyperuricaemia & 1 & 0.2 & 1 & 0.4 & 0 & 0.0 & 1.00 \\
\hline Hyperthyroid & 3 & 0.6 & 2 & 0.8 & 1 & 0.4 & 1.00 \\
\hline Others & 16 & $3 \cdot 3$ & 9 & $3 \cdot 8$ & 7 & $2 \cdot 9$ & 0.40 \\
\hline Medication within $5 \mathrm{~d}$ before urine collection (yes) & 24 & $5 \cdot 0$ & 14 & $5 \cdot 8$ & 10 & $4 \cdot 2$ & 0.54 \\
\hline Not consuming drug & 455 & $95 \cdot 0$ & 226 & $94 \cdot 2$ & 229 & $95 \cdot 8$ & \\
\hline Antihypertensive drugs & 18 & $3 \cdot 8$ & 13 & 5.4 & 5 & $2 \cdot 1$ & \\
\hline Diuretics & 1 & 0.2 & 0 & 0.0 & 1 & 0.4 & \\
\hline Antihyperglycaemic agent & 1 & 0.2 & 0 & 0.0 & 1 & 0.4 & \\
\hline Antiplatelet drug & 1 & 0.2 & 0 & 0.0 & 1 & 0.4 & \\
\hline Antianginal drug & 1 & $0 \cdot 2$ & 1 & 0.4 & 0 & 0.0 & \\
\hline Supplement/herbal & 1 & 0.2 & 0 & 0.0 & 1 & 0.4 & \\
\hline Nootropic drug & 1 & 0.2 & 0 & 0.0 & 1 & 0.4 & \\
\hline \multicolumn{8}{|l|}{ Smoking habit and consuming alcohol } \\
\hline Smoker (yes) & 144 & $30 \cdot 1$ & 144 & $60 \cdot 0$ & 0 & 0.0 & $<0.001$ \\
\hline \multicolumn{8}{|l|}{ Number of cigarettes ( $n$ 140) } \\
\hline $1-6$ cigarettes/d & & & 33 & $23 \cdot 6$ & & & \\
\hline $7-12$ cigarettes/d & & & 92 & $65 \cdot 7$ & & & \\
\hline$>13$ cigarettes $/ d$ & & & 15 & $10 \cdot 7$ & & & \\
\hline Past smoker (yes) & 179 & $37 \cdot 4$ & 179 & 74.6 & 0 & 0.0 & $<0.001$ \\
\hline Couple is smoker (yes) & 140 & $29 \cdot 2$ & 1 & 0.4 & 139 & $58 \cdot 2$ & $<0.001$ \\
\hline Consuming alcohol (yes) & 2 & 0.4 & 2 & 0.8 & 0 & 0.0 & $<0.001$ \\
\hline \multicolumn{8}{|l|}{ Blood pressure $(\mathrm{mmHg})$} \\
\hline SBPII & $139 \cdot 3$ & $24 \cdot 7$ & 139.9 & 23.9 & $138 \cdot 7$ & $25 \cdot 5$ & 0.60 \\
\hline DBPII & $87 \cdot 4$ & $11 \cdot 2$ & $87 \cdot 4$ & $11 \cdot 8$ & $87 \cdot 3$ & $10 \cdot 7$ & 0.87 \\
\hline HR (times/min) $\ddagger$ & $82 \cdot 1$ & $9 \cdot 6$ & $81 \cdot 2$ & $9 \cdot 2$ & 83.0 & $9 \cdot 8$ & 0.04 \\
\hline $\mathrm{Ht}(\mathrm{cm})$ & 155.5 & $7 \cdot 3$ & $159 \cdot 8$ & $5 \cdot 9$ & $151 \cdot 1$ & $6 \cdot 0$ & $<0.001$ \\
\hline Wt $(\mathrm{kg})$ & $53 \cdot 8$ & 10.5 & 53.5 & $10 \cdot 4$ & $54 \cdot 2$ & $10 \cdot 7$ & 0.46 \\
\hline $\mathrm{BMI}\left(\mathrm{kg} / \mathrm{m}^{2}\right)$ & $22 \cdot 3$ & $4 \cdot 2$ & $20 \cdot 9$ & 3.7 & 23.7 & $4 \cdot 2$ & $<0.001$ \\
\hline Underweight $(<18.5)$ & 93 & $19 \cdot 4$ & 64 & $26 \cdot 7$ & 29 & $12 \cdot 1$ & $<0.001$ \\
\hline Normal (18.5-24.9) & 270 & $56 \cdot 4$ & 146 & $60 \cdot 8$ & 124 & 51.9 & \\
\hline Overweight (25.0-29.9) & 99 & $20 \cdot 7$ & 27 & $11 \cdot 3$ & 72 & $30 \cdot 1$ & \\
\hline Obesity I (30.0-34.9) & 17 & 3.5 & 3 & $1 \cdot 3$ & 14 & 5.9 & \\
\hline Barthel index score, independent ( $n$ 240) & 236 & $98 \cdot 3$ & 117 & $97 \cdot 5$ & 119 & $99 \cdot 2$ & 0.44 \\
\hline PAL $(M E T \times h)$ & $71 \cdot 2$ & $56 \cdot 7$ & $67 \cdot 2$ & $56 \cdot 4$ & $75 \cdot 2$ & $56 \cdot 7$ & 0.12 \\
\hline \multicolumn{8}{|l|}{ Environment§ } \\
\hline Temperature $\left({ }^{\circ} \mathrm{C}\right)$ & $27 \cdot 5$ & 0.4 & $27 \cdot 6$ & 0.5 & $27 \cdot 5$ & 0.5 & 0.02 \\
\hline Humidity (\%) & $56 \cdot 9$ & 3.4 & $56 \cdot 5$ & 3.5 & $57 \cdot 2$ & 3.2 & 0.02 \\
\hline
\end{tabular}

NCD, non-communicable disease; SBP, systolic blood pressure; BBP, diastolic blood pressure; HR, heart rate; Ht, height; Wt, weight; PAL, physical activity level; MET, metabolic equivalents.

* The statistic was based on Student's $t$ test and $\chi^{2}$ test.

† This NCD was reported by participant and only diagnosed cases; therefore, undiagnosed not included

† It was measured three times; this value was mean of three times measurements.

$\S$ It was measured once per $d$ at 10.00 hours; this value was the mean of two measurements.

II It was measured three times; this value was the mean of the second and third measurements. 
Table 2. Concordance analyses between day 1 and 2 urine collections on the sodium and potassium results* $(n 380)$ (Numbers and percentages)

\begin{tabular}{|c|c|c|c|c|c|c|c|c|c|c|c|c|c|c|c|c|}
\hline \multirow[b]{4}{*}{ Measurements of urine excretion } & \multicolumn{16}{|c|}{ Day 2 urine collection } \\
\hline & \multicolumn{8}{|c|}{$\mathrm{Na}$ excretion } & \multicolumn{8}{|c|}{ K excretion } \\
\hline & \multicolumn{2}{|c|}{ Low tertile } & \multicolumn{2}{|c|}{$\begin{array}{l}\text { Median } \\
\text { tertile }\end{array}$} & \multicolumn{2}{|c|}{ High tertile } & \multicolumn{2}{|c|}{ Total } & \multicolumn{2}{|c|}{ Low tertile } & \multicolumn{2}{|c|}{$\begin{array}{c}\text { Median } \\
\text { tertile }\end{array}$} & \multicolumn{2}{|c|}{ High tertile } & \multicolumn{2}{|c|}{ Total } \\
\hline & $n$ & $\%$ & $n$ & $\%$ & $n$ & $\%$ & $n$ & $\%$ & $n$ & $\%$ & $n$ & $\%$ & $n$ & $\%$ & $n$ & $\%$ \\
\hline \multicolumn{17}{|l|}{ Day 1 urine collection } \\
\hline Median tertile & 38 & $10 \cdot 0$ & 56 & $14 \cdot 7$ & 31 & $8 \cdot 2$ & 125 & $32 \cdot 9$ & 23 & $6 \cdot 1$ & 64 & $16 \cdot 8$ & 31 & $8 \cdot 2$ & 118 & $31 \cdot 1$ \\
\hline High tertile & 13 & 3.4 & 29 & $7 \cdot 6$ & 83 & $21 \cdot 8$ & 125 & 32.9 & 8 & $2 \cdot 1$ & 30 & $7 \cdot 9$ & 81 & $21 \cdot 3$ & 119 & $31 \cdot 3$ \\
\hline Total & 131 & 34.5 & 126 & $33 \cdot 2$ & 123 & $32 \cdot 4$ & 380 & $100 \cdot 0$ & 138 & $36 \cdot 3$ & 124 & $32 \cdot 6$ & 118 & $31 \cdot 1$ & 380 & $100 \cdot 0$ \\
\hline Mean difference & \multirow{2}{*}{\multicolumn{8}{|c|}{$\begin{array}{c}3.1 \\
-0.96,7.07\end{array}$}} & \multicolumn{8}{|c|}{0.8} \\
\hline $95 \% \mathrm{Cl}$ & & & & & & & & & \multicolumn{8}{|c|}{$0.05,1.5$} \\
\hline Limits of agreement & \multicolumn{8}{|c|}{$-75,81$} & \multirow{2}{*}{\multicolumn{8}{|c|}{$-13 \cdot 3,14 \cdot 9$}} \\
\hline$r$ & \multicolumn{8}{|c|}{0.6} & \multicolumn{5}{|c|}{0.8} & & & \\
\hline$P$ & \multicolumn{8}{|c|}{$<0.001$} & \multicolumn{8}{|c|}{$\begin{array}{c}<0.001 \\
0.48\end{array}$} \\
\hline
\end{tabular}

$r$, Correlation coefficient; $\kappa$, agreement $\kappa$.

* This analysis conducted only with two successful urine collections were included in the analyses.

† To measure the concordance among day 1 and 2 measurements of 24-h urine, we used Bland-Altman, linear regression, Spearman's correlation and Cohen's $\kappa$ test ( $\mathrm{k}$ ).

Table 3. Results of 24-h urine collection by sex

(Mean values and standard deviations)

\begin{tabular}{|c|c|c|c|c|c|c|}
\hline & \multicolumn{2}{|c|}{ Men $(n 240)$} & \multicolumn{2}{|c|}{$\begin{array}{l}\text { Women } \\
(n \text { 239) }\end{array}$} & \multicolumn{2}{|c|}{ Total $(n 479)$} \\
\hline & Mean & SD & Mean & SD & Mean & SD \\
\hline Collected volume (ml) & $1036 \cdot 4$ & $482 \cdot 6$ & 1014.0 & $469 \cdot 0$ & $1025 \cdot 2$ & 475.5 \\
\hline Creatinine excretion $(\mathrm{mg} / \mathrm{d})$ & $1003 \cdot 7$ & 343.4 & $727 \cdot 1$ & $222 \cdot 0$ & 865.7 & $320 \cdot 4$ \\
\hline Creatinine ratio $(\%)^{\star}$ & $101 \cdot 3$ & $30 \cdot 2$ & 72.6 & $19 \cdot 4$ & $87 \cdot 0$ & $29 \cdot 2$ \\
\hline $\mathrm{Na}$ excretion $(\mathrm{mmol} / \mathrm{d})$ & $102 \cdot 8$ & 43.7 & $100 \cdot 6$ & $36 \cdot 4$ & 101.5 & $40 \cdot 3$ \\
\hline K excretion $(\mathrm{mmol} / \mathrm{d})$ & $25 \cdot 0$ & 8.9 & 23.4 & $8 \cdot 2$ & $24 \cdot 2$ & $8 \cdot 6$ \\
\hline $\mathrm{K}$ excretion (mmol/g Cr)† & $26 \cdot 6$ & $10 \cdot 8$ & $33 \cdot 1$ & $11 \cdot 4$ & $30 \cdot 1$ & $12 \cdot 0$ \\
\hline Na:K ratioł & $6 \cdot 6$ & $2 \cdot 7$ & $6 \cdot 7$ & $2 \cdot 6$ & $6 \cdot 7$ & $2 \cdot 7$ \\
\hline
\end{tabular}

* The ratio of observed to expected creatinine excretion calculated using the equations of Joossens et al. If the ratio was $<60 \%$ or $>140 \%$, the collection was considered unsuccessful. † The unit $(\mathrm{mmol} / \mathrm{g} \mathrm{Cr})$ indicated the excretion of the electrolyte $(\mathrm{mmol})$ per $1 \mathrm{~g}$ excretion of creatinine.

$\ddagger$ Ratio of $\mathrm{Na}(\mathrm{mg} / \mathrm{d}): \mathrm{K}(\mathrm{mg} / \mathrm{d})$.

PAL were associated with higher $\mathrm{K}$ excretions. For habitual intake (Table 6), none of the $\mathrm{K}$ intakes met the recommended value in both sexes. However, $20 \%$ of participants met the salt intake recommendation. Additionally, there were no significant differences between groups in environments of lower and higher temperatures and humidities with urine excretion (online Supplemental Material 1).

\section{Discussion}

To the best of our knowledge, this is the first study to investigate $\mathrm{Na}$ and K excretions using 24-h urine collection, a 'gold standard' method ${ }^{(65)}$, in Indonesians based on a representative sample in a city of Indonesia. We collected urine samples over two 24 -h periods to determine the $\mathrm{Na}$ and $\mathrm{K}$ excreted. The results of the concordance analysis showed a good agreement between the two measurements (days 1 and 2) even though considerable day-to-day variations existed in both the $\mathrm{Na}$ and $\mathrm{K}$ excretions into 24-h urine. Therefore, the $24-\mathrm{h}$ urine data were confirmed as reliable for use in the analysis.

In the present study, mean $\mathrm{Na}$ intake was $102.8 \mathrm{mmol} / \mathrm{d}(6 \mathrm{~g}$ $\mathrm{NaCl})$ in men and $100.6 \mathrm{mmol} / \mathrm{d}(5.9 \mathrm{~g} \mathrm{NaCl})$ in women. These findings are higher than the recommended values of $<73.1 \mathrm{mmol} / \mathrm{d}(5 \mathrm{~g} \mathrm{NaCl})$ for $\mathrm{Na}$ excretion ${ }^{(66)}$. Previous studies have reported that the $\mathrm{Na}$ intake among Indonesian was $6.9 \mathrm{~g}$ $\mathrm{NaCl}$ ( $n$ 15, adult women in urban area) ${ }^{(27)}$ and $6 \cdot 16 \mathrm{~g} \mathrm{NaCl}(n$ 51 , older adult women in coastal area) ${ }^{(28)}$. Both studies calculated the $\mathrm{Na}$ intake using a single 24-h urine excretion. A previous study that used 24-h dietary recall reported higher values than the 24-h urine collection, that is, $9.4 \mathrm{~g} \mathrm{NaCl}(n 395$ women in urban area) ${ }^{(26)}$. This present study has similar result with the previous Indonesian which used 24-h urine excretion. Notwithstanding, the awareness of Indonesian people of the benefits of avoiding salty food is quite high, at $68.6 \%$; however, the average $\mathrm{Na}$ intake is still high ${ }^{(28)}$, suggesting that awareness 
Table 4. Results of 24-h urine collection by sex and other factors (age, BMl and physical activity level (PAL); $n$ 479)

(Mean values and standard deviations)

\begin{tabular}{|c|c|c|c|c|c|c|c|c|c|c|c|c|c|c|c|c|}
\hline \multirow[b]{2}{*}{ Sex } & \multirow[b]{2}{*}{ Categories } & \multirow[b]{2}{*}{$n$} & \multicolumn{2}{|c|}{$\mathrm{BMI}\left(\mathrm{kg} / \mathrm{m}^{2}\right)$} & \multicolumn{2}{|c|}{$\begin{array}{l}\text { Collected volume } \\
(\mathrm{ml})\end{array}$} & \multicolumn{2}{|c|}{$\begin{array}{l}\text { Creatinine excre- } \\
\text { tion }(\mathrm{mg} / \mathrm{d})\end{array}$} & \multicolumn{2}{|c|}{$\begin{array}{c}\text { Creatinine ratio } \\
(\%)^{*}\end{array}$} & \multicolumn{2}{|c|}{$\begin{array}{l}\text { Na excretion } \\
(\mathrm{mmol} / \mathrm{d})\end{array}$} & \multicolumn{2}{|c|}{$\begin{array}{c}\text { K excretion } \\
(\mathrm{mmol} / \mathrm{d})\end{array}$} & \multicolumn{2}{|c|}{$\mathrm{Na}$ K ratio† } \\
\hline & & & Mean & SD & Mean & SD & Mean & SD & Mean & SD & Mean & SD & Mean & SD & Mean & SD \\
\hline \multirow[t]{15}{*}{ Men $(n 240)$} & Age (years) & & & & & & & & & & & & & & & \\
\hline & $20-39$ & 34 & 21.5 & $4 \cdot 3$ & $1068 \cdot 9$ & 481.3 & $1208 \cdot 0$ & $372 \cdot 2$ & $118 \cdot 6$ & 36.4 & 111.6 & 39.5 & $22 \cdot 1$ & $8 \cdot 3$ & $8 \cdot 4$ & $3 \cdot 6$ \\
\hline & $40-59$ & 85 & 21.9 & 3.7 & 1134.2 & $521 \cdot 0$ & $1090 \cdot 2$ & $348 \cdot 3$ & $104 \cdot 2$ & $32 \cdot 1$ & 106.8 & 47.6 & $26 \cdot 3$ & 8.7 & 6.4 & $2 \cdot 7$ \\
\hline & $60-79$ & 110 & $20 \cdot 3$ & $3 \cdot 3$ & 979.0 & 444.5 & $921 \cdot 1$ & 268.6 & $97 \cdot 2$ & $23 \cdot 0$ & $99 \cdot 6$ & 42.5 & $25 \cdot 2$ & $9 \cdot 3$ & 6.3 & 2.4 \\
\hline & 80-99 & 11 & $17 \cdot 7$ & $2 \cdot 2$ & $753 \cdot 0$ & 399.2 & 529.4 & 167.7 & $67 \cdot 0$ & $22 \cdot 0$ & 71.8 & 22.8 & $19 \cdot 9$ & 7.8 & 5.8 & 1.6 \\
\hline & $\mathrm{BMI}\left(\mathrm{kg} / \mathrm{m}^{2}\right)$ & & & & & & & & & & & & & & & \\
\hline & Underweight $(<18.5)$ & 64 & $16 \cdot 9$ & 1.4 & 869.7 & 389.5 & 835.9 & $296 \cdot 2$ & $103 \cdot 2$ & $29 \cdot 7$ & $83 \cdot 3$ & 34.9 & $22 \cdot 1$ & 8.2 & $6 \cdot 2$ & 2.8 \\
\hline & Normal (18.5-24.9) & 146 & $21 \cdot 2$ & 1.7 & $1091 \cdot 1$ & 511.7 & $1024 \cdot 3$ & $312 \cdot 6$ & 101.8 & $31 \cdot 2$ & $104 \cdot 3$ & $41 \cdot 1$ & $25 \cdot 3$ & 9.2 & 6.7 & 2.8 \\
\hline & Overweight (25.0-29.9) & 27 & $27 \cdot 0$ & 1.4 & $1109 \cdot 6$ & $441 \cdot 1$ & $1212 \cdot 4$ & 383.0 & 94.4 & 27.5 & 128.0 & 48.8 & $27 \cdot 9$ & $7 \cdot 3$ & $7 \cdot 0$ & $2 \cdot 4$ \\
\hline & Obesity $(>30)$ & 3 & 35.4 & 3.7 & 1267.5 & 536.9 & $1702 \cdot 7$ & $285 \cdot 0$ & 101.5 & $12 \cdot 6$ & $199 \cdot 2$ & $59 \cdot 1$ & $39 \cdot 3$ & 8.5 & 7.8 & $2 \cdot 3$ \\
\hline & PAL $(M E T \times h) \ddagger$ & & & & & & & & & & & & & & & \\
\hline & Q1 (9.6) & 76 & 21.4 & 3.8 & $993 \cdot 1$ & 507.4 & $949 \cdot 3$ & 356.7 & 93.6 & $28 \cdot 3$ & $97 \cdot 0$ & 38.6 & $23 \cdot 3$ & $9 \cdot 1$ & 6.8 & 2.7 \\
\hline & Q2 (41.6) & 45 & $20 \cdot 6$ & $4 \cdot 2$ & $1095 \cdot 9$ & 489.0 & 977.4 & 258.6 & 102.5 & $22 \cdot 1$ & 114.5 & 49.8 & $26 \cdot 0$ & 9.4 & 7.0 & $2 \cdot 9$ \\
\hline & Q3 (80.2) & 61 & $21 \cdot 2$ & 3.6 & $1058 \cdot 0$ & 497.3 & $1016 \cdot 6$ & 343.6 & $100 \cdot 9$ & 29.5 & $101 \cdot 1$ & 38.8 & $25 \cdot 2$ & 7.9 & $6 \cdot 4$ & $2 \cdot 8$ \\
\hline & Q4 (148.9) & 58 & $20 \cdot 2$ & $3 \cdot 1$ & $1024 \cdot 1$ & 432.5 & $1081 \cdot 8$ & 374.4 & $111 \cdot 1$ & $36 \cdot 2$ & $102 \cdot 1$ & 49.5 & $26 \cdot 0$ & 9.4 & $6 \cdot 2$ & $2 \cdot 8$ \\
\hline Women & Age (years) & & & & & & & & & & & & & & & \\
\hline \multirow{14}{*}{ (n 239) } & $20-39$ & 35 & 24.8 & 4.4 & $1108 \cdot 1$ & 436.7 & 895.5 & 208.9 & $83 \cdot 3$ & 21.5 & 116.7 & 29.4 & 21.6 & 6.6 & 8.8 & 3.3 \\
\hline & $40-59$ & 84 & 24.8 & $4 \cdot 0$ & $1053 \cdot 4$ & 480.1 & $792 \cdot 1$ & 193.4 & $75 \cdot 0$ & 17.7 & 114.8 & 38.1 & 24.8 & 8.0 & 7.3 & 2.5 \\
\hline & $60-79$ & 112 & $22 \cdot 8$ & $4 \cdot 1$ & $961 \cdot 3$ & 467.7 & 639.4 & $200 \cdot 1$ & 67.9 & $18 \cdot 4$ & 86.7 & 30.7 & $23 \cdot 2$ & 8.7 & 5.9 & 1.9 \\
\hline & 80-99 & 8 & $19 \cdot 9$ & $2 \cdot 8$ & $927 \cdot 2$ & 483.5 & 535.0 & 167.5 & $68 \cdot 3$ & 21.8 & $70 \cdot 8$ & $29 \cdot 1$ & 19.8 & $5 \cdot 2$ & $5 \cdot 3$ & 1.4 \\
\hline & $\mathrm{BMI}\left(\mathrm{kg} / \mathrm{m}^{2}\right)$ & & & & & & & & & & & & & & & \\
\hline & Underweight $(<18.5)$ & 29 & $16 \cdot 6$ & 1.4 & 855.0 & $470 \cdot 0$ & $545 \cdot 1$ & 199.9 & $76 \cdot 9$ & $26 \cdot 7$ & $76 \cdot 1$ & $26 \cdot 2$ & 18.5 & $5 \cdot 1$ & $6 \cdot 4$ & 2.7 \\
\hline & Normal (18.5-24.9) & 124 & $22 \cdot 2$ & 1.7 & $1008 \cdot 0$ & 467.9 & 695.2 & 195.6 & 74.3 & $19 \cdot 0$ & 94.2 & 31.9 & 22.9 & 7.6 & 6.6 & 2.6 \\
\hline & Overweight (25.0-29.9) & 72 & $27 \cdot 6$ & 1.4 & $1056 \cdot 9$ & 480.1 & $825 \cdot 1$ & 211.6 & 69.7 & $16 \cdot 8$ & $115 \cdot 3$ & $40 \cdot 0$ & $25 \cdot 3$ & 9.3 & $7 \cdot 2$ & 2.6 \\
\hline & Obesity $(>30)$ & 14 & 31.5 & $1 \cdot 1$ & $1176 \cdot 1$ & 354.5 & 882.6 & $216 \cdot 3$ & $64 \cdot 3$ & 14.4 & 128.5 & 23.9 & 28.0 & 6.8 & $7 \cdot 1$ & 1.8 \\
\hline & PAL $(M E T \times h) \ddagger$ & & & & & & & & & & & & & & & \\
\hline & Q1 (19.8) & 45 & 23.5 & 4.6 & $1020 \cdot 3$ & 541.8 & 663.8 & 245.8 & $68 \cdot 1$ & $19 \cdot 0$ & $88 \cdot 8$ & 34.4 & $22 \cdot 4$ & $8 \cdot 2$ & $6 \cdot 1$ & $2 \cdot 0$ \\
\hline & Q2 (40.7) & 74 & $24 \cdot 3$ & 4.1 & $1037 \cdot 3$ & 474.0 & 715.6 & $225 \cdot 9$ & $69 \cdot 3$ & $18 \cdot 7$ & $101 \cdot 0$ & 37.9 & 22.8 & 7.6 & 6.9 & 2.5 \\
\hline & Q3 (74.3) & 60 & 23.4 & 4.2 & 1041.4 & 437.6 & $725 \cdot 7$ & 212.8 & 72.9 & 19.6 & 104.1 & $36 \cdot 1$ & 23.8 & 9.4 & $7 \cdot 1$ & $2 \cdot 9$ \\
\hline & Q4 (160.1) & 60 & $23 \cdot 3$ & 4.2 & 953.2 & 440.1 & 790.1 & 195.1 & 79.9 & 18.8 & 104.6 & $35 \cdot 1$ & 24.5 & 7.5 & 6.7 & $2 \cdot 6$ \\
\hline
\end{tabular}

MET, metabolic equivalents; $Q$, quantile.

* The ratio of observed to expected creatinine excretion calculated using the equations of Joossens et al. If the ratio was $<60 \%$ or $>140 \%$, the collection was considered unsuccessful.

: $\mathrm{K}(\mathrm{mg} / \mathrm{d})$.

PAL categorised into quartiles, and mean PAL for each category was shown in parentheses. 
alone is not enough to decrease salt intake. While most people know that they should reduce their salt intake, there may be confusion as to which foods should be avoided. Therefore, an exploration of commonly consumed Indonesian foods (dietary habit) with high $\mathrm{Na}$ content is required.

While the Indonesian $\mathrm{Na}$ intake is high, other East Asian countries (Korea, China and Japan) reported a higher Na intake than that observed in the present study ${ }^{(18,23,67-69)}$. We suggest two reasons to explain these results. First, the characteristics of foods eaten commonly in other East Asian countries and in Indonesia may have influenced the intake of $\mathrm{Na}^{(23,56)}$, while Indonesian people usually consume noodle products, salty seafood products, composite foods, foods with coconut milk and fried foods which contain high $\mathrm{Na}^{(70)}$. However, people from other East Asian countries may consume more high-Na-containing foods than Indonesians. For example, Japanese people consume miso and soya sauce, both of which are very high in $\mathrm{Na}$. Second, a previous study found that $14 \%$ of $\mathrm{Na}$ intake was excreted in faeces and sweat ${ }^{(33)}$. This percentage is expected to be higher in a tropical country such as Indonesia with a mean temperature of $27.5^{\circ} \mathrm{C}$ and humidity of $56.9 \%$. The mean temperature in other East Asian countries is lower than that in Indonesia. Thus, there is a possibility that the actual $\mathrm{Na}$ intake is higher than the observed $\mathrm{Na}$ intake in the present study.

The mean $\mathrm{K}$ excretion among Indonesian people was lower than the recommended values for $\mathrm{K}$ intake ${ }^{(64)}$. Previous studies in Indonesia reported that the $\mathrm{K}$ intake among older adults was $48.5 \mathrm{mmol} / \mathrm{d}(1895 \mathrm{mg} \mathrm{K})$ in men, $41.8 \mathrm{mmol} / \mathrm{d}$ (1634 $\mathrm{mg} \mathrm{K}$ ) in women ${ }^{(26)}$, and among adult diabetic patients, it was $37.4 \mathrm{mmol} / \mathrm{d}(1460 \mathrm{mg} \mathrm{K})^{(71)}$, which is higher than that reported in the present study. This may have been because those previous studies used 24-h dietary recall and semi-quantitative FFQ, which tends to overestimate. Nevertheless, that result was still below the recommended values for $\mathrm{K}$ intake. The national survey by Indonesia's government showed that almost all Indonesians consumed, per $\mathrm{d}$, fewer than five servings of fruits/vegetables, which are high in $\mathrm{K}^{(36)}$. Indonesian people would be needed to consume more food containing K.

A multivariate linear regression showed that the BMI was significantly associated with $\mathrm{Na}$ and $\mathrm{K}$ excretion in both sexes. A higher BMI indicated a higher food consumption, and higher food consumption reflects higher nutrient intake ${ }^{(14,72)}$. Individuals with a higher BMI tend to have unhealthier lifestyles than those with a lower BMI, including a preference for salty foods ${ }^{(73)}$. Careful attention should be paid to individuals with a high BMI.

Age was associated with $\mathrm{Na}$ excretion in both sexes with $\mathrm{K}$ excretion and the Na:K ratio only among men. Younger and older adults have different preferences for food selection. The younger select more variety and modern food (i.e. bread, noodle, confectioneries and meat) which is known to result in a higher Na intake ${ }^{(56,74,75)}$. Furthermore, a previous study showed that younger age, male sex and smoking were associated with a less healthy diet ${ }^{(74,76)}$. Because of the high prevalence of noncommunicable diseases in older adults, some older adults may have had the opportunity to receive healthy diet education ${ }^{(77)}$, which could have changed their eating habits. Younger adults would have had less opportunity to receive education regarding 
Table 6. Estimated proportion of participants whose sodium and potassium intakes met the recommended values $(<5 \mathrm{~g} / \mathrm{d})$ in the population analysed* $(n 380)$

\begin{tabular}{|c|c|c|c|c|c|c|}
\hline & Recommended by & $\begin{array}{l}\text { Recommended values for } \\
\text { nutrient intake }(\mathrm{mmol} / \mathrm{d})\end{array}$ & $\begin{array}{l}\text { Recommended values adjusted } \\
\text { for excretion }(\mathrm{mmol} / \mathrm{d}) \dagger\end{array}$ & \multicolumn{3}{|c|}{$\begin{array}{c}\text { Probability of meeting the } \\
\text { recommended values adjusted } \\
\text { for excretion (\%) }\end{array}$} \\
\hline Nał & Indonesia government & $85 \cdot 0$ & $73 \cdot 1$ & $19 \cdot 7$ & $22 \cdot 5$ & $16 \cdot 5$ \\
\hline $\mathrm{K} \S$ & and $\mathrm{WHO}$ & $90 \cdot 0$ & $69 \cdot 3$ & $0 \cdot 0$ & $0 \cdot 0$ & 0.0 \\
\hline
\end{tabular}

* This analysis conducted only with two successful urine collections were included in the analyses. The estimation of habitual Na and K intakes was simulated using HabitDist software. † These values were divided by 0.86 for $\mathrm{Na}$ and 0.77 for $\mathrm{K}$ to apply the recommendations for dietary intake to the excretion data ${ }^{(61)}$.

$\ddagger 1 \mathrm{mmol} \mathrm{Na}=23.0 \mathrm{mg} \mathrm{Na}=58.5 \mathrm{mg} \mathrm{NaCl}$.

$\S 1 \mathrm{mmol} \mathrm{K}=39 \cdot 1 \mathrm{mg} \mathrm{K}$.

healthy diets, and younger age may have been related to the higher $\mathrm{Na}$ and lower $\mathrm{K}$ excretion in the present study. Thus, the target population for the salt education programme should be expanded to younger adults.

In the present study, more than $80 \%$ of the participants were estimated to consume more $\mathrm{Na}$ than the recommended value $(<5 \mathrm{~g} / \mathrm{d})$. For $\mathrm{K}$ intake, no participant $(0 \%)$ met the recommended value $(>3510 \mathrm{mg} / \mathrm{d})$. Therefore, there is an urgent need to develop interventions to reduce $\mathrm{Na}$ intake and to increase $\mathrm{K}$ intake. In Indonesia, there are Integrated Guidance Posts (Posbindu), wherein all community-dwelling people gather at least once a month to measure their blood pressure and body weight ${ }^{(78)}$. Thus, conducting a salt reduction programme in the Integrated Guidance Posts may be an effective intervention for people in the community.

The present study had several limitations. First, to minimise any errors and to improve the feasibility of obtaining enough samples, we decided to collect data in one city, and all the accumulated urine was analysed at the same clinical testing company. Second, some participants had a history of other diseases and may have taken medications that had an effect on $\mathrm{Na}$ and $\mathrm{K}$ excretion. To confirm the assumption, we recalculated the $\mathrm{Na}$ and $\mathrm{K}$ excretions after excluding the participants with hypertension based on blood measurement and/or those who took antihypertensive and diuretic drugs ( $n$ total $=297$; men $=149$ and women $=148$; data not shown). The mean values for $\mathrm{Na}$ and $\mathrm{K}$ urine excretions were 99.7 and $24.6 \mathrm{mmol} / \mathrm{d}$ in men, and 100.8 and $22.5 \mathrm{mmol} / \mathrm{d}$ in women, respectively. These excretion values were almost the same as those obtained in our study population. Third, the biomarkers measured in the urine sample were $\mathrm{Cr}$, Na and $\mathrm{K}$. However, on urine collection day 2, we only measured urine $\mathrm{Na}$ and $\mathrm{K}$, due to budget constraints. Therefore, we used a different method to measure the successful urine collection in the 24-h urine collection between days 1 and 2. However, both methods have been used and validated in previous studies ${ }^{(48,54,55)}$. Fourth, the independent variables in the present study were reported as factors related to energy intake which was the major predictor of salt intake. However, the association between the variables and salt intake in each population and in the country was slightly different in the previous studies ${ }^{(18,19,79)}$.

In conclusion, we estimated $\mathrm{Na}$ and $\mathrm{K}$ intakes among community-dwelling adults in an Indonesian city and found a significantly positive association of BMI with Na excretion. The mean salt intake among the participants was estimated to be higher than the values recommended by the Indonesian government. Further, the $\mathrm{K}$ intake was lower compared with the recommended values. From the estimation of habitual $\mathrm{Na}$ and $\mathrm{K}$ intakes, the number of participants who met the recommended value was low. In the future, it will be essential to consider the Indonesian food dietary patterns when intervention programmes against high $\mathrm{Na}$ and low $\mathrm{K}$ are planned in this country.

\section{Acknowledgements}

The authors sincerely acknowledge the Nganjuk government for providing census data. The authors also thank all the participants for their contribution to the present study. The authors are also grateful to Dr Kentaro Murakami for providing valuable advice during the data analysis and assistance with the interpretation of the results.

This work was supported by a grant from the Nestlé Foundation for the study of problems of nutrition in the world, Lausanne, Switzerland. The first author (D. W. S.) was supported by the Indonesia Endowment Fund for Education (LPDP RI). The Nestlé Foundation and LPDP RI had no role in the design and analysis of the study or in the writing of this manuscript.

D. W. S. designed the study, collected data, performed statistical analysis and drafted the paper. M. N. W. and N. Y. M. contributed to the study design, study coordination, supervision, supported the analysis and helped in drafting the paper. S. S. helped in study design, supervision, supported the statistical analysis, interpretation of the results, and helped in writing the paper. J. S. was involved in the establishment of the study area and helped in writing the paper. All authors read and approved the final manuscript to be published.

The authors declare that they have no conflicts of interest.

\section{Supplementary material}

For supplementary material referred to in this article, please visit https://doi.org/10.1017/S0007114521000271

\section{References}

1. Ministry of Health of the Republic of Indonesia (2017) Health Profile of Indonesia in 2016 (in Indonesian). Jakarta: Ministry of Health of the Republic of Indonesia. 
2. Aburto NJ, Hanson S, Gutierrez H, et al. (2013) Effect of increased potassium intake on cardiovascular risk factors and disease: systematic review and meta-analyses. Br Med J $34 \mathbf{6}$ f1378.

3. Judd SE, Aaron KJ, Letter AJ, et al. (2013) High sodium:potassium intake ratio increases the risk for all-cause mortality: the REasons for Geographic and Racial Differences in Stroke (REGARDS) study. J Nutr Sci $\mathbf{2}$, e13.

4. Okayama A, Okuda N, Miura K, et al. (2016) Dietary sodium-topotassium ratio as a risk factor for stroke, cardiovascular disease and all-cause mortality in Japan: the NIPPON DATA80 Cohort Study. BMJ Open 6, e011632.

5. Alma JA, Fiona T, Nicole M, et al. (2014) Reduced dietary salt for the prevention of cardiovascular disease (Review). Cochrane Database Syst Rev, issue 12, CD009217.

6. Graudal N, Jürgens G, Baslund B, et al. (2014) Compared with usual sodium intake, low- and excessive-sodium diets are associated with increased mortality: a meta-analysis. Am JHypertens 27, 1129-1137.

7. O'Donnell M, Mente A, Rangarajan S, et al. (2014) Urinary sodium and potassium excretion, mortality, and cardiovascular events. N Engl J Med 371, 612-623.

8. Graudal NA, Hubeck-Graudal T \& Jurgens G (2017) Effects of low sodium diet versus high sodium diet on blood pressure, renin, aldosterone, catecholamines, cholesterol, and triglyceride. Cochrane Database Syst Rev, issue 11, CD004022.

9. Mente A, O'Donnell M, Rangarajan S, et al. (2018) Urinary sodium excretion, blood pressure, cardiovascular disease, and mortality: a community-level prospective epidemiological cohort study. Lancet 392, 496-506.

10. O'Donnell M, Mente A, Rangarajan S, et al. (2019) Joint association of urinary sodium and potassium excretion with cardiovascular events and mortality: prospective cohort study. $B M J$ 364, 1772

11. Aburto NJ, Ziolkovska A, Hooper L, et al. (2013) Effect of lower sodium intake on health: systematic review and meta-analyses. BMJ 346, f1326.

12. Pfister R, Michels G, Sharp SJ, et al. (2014) Estimated urinary sodium excretion and risk of heart failure in men and women in the EPIC-Norfolk study. Eur J Heart Fail 16, 394-402.

13. O'Donnell MJ, Mente A, Smyth A, et al. (2013) Salt intake and cardiovascular disease: why are the data inconsistent? Eur Heart J 34, 1034-1040.

14. Brown IJ, Tzoulaki I, Candeias V, et al. (2009) Salt intakes around the world: implications for public health. Int $J$ Epidemiol 38, 791-813.

15. Mccarron DA, Kazaks AG, Geerling JC, et al. (2013) Normal range of human dietary sodium intake: a perspective based on 24-hour urinary sodium excretion worldwide. $\mathrm{Am} \mathrm{J}$ Hypertens 26, 1218-1223.

16. Mozaffarian D, Fahimi S, Singh GM, et al. (2014) Global sodium consumption and death from cardiovascular causes. $N$ Engl J Med 371, 624-634.

17. Sadler K, Nicholson S, Steer T, et al. (2011) National Diet and Nutrition Survey - Assessment of Dietary Sodium in Adults (Aged 19 to 64 Years) in England, 2011. London: Department of Health.

18. Asakura K, Uechi K, Sasaki Y, et al. (2014) Estimation of sodium and potassium intakes assessed by two $24 \mathrm{~h}$ urine collections in healthy Japanese adults: a nationwide study. Br J Nutr $\mathbf{1 1 2}$ $1195-1205$.

19. Ortega RM, López-Sobaler AM, Ballesteros JM, et al. (2011) Estimation of salt intake by $24 \mathrm{~h}$ urinary sodium excretion in a representative sample of Spanish adults. Br J Nutr 105, 787-794.
20. Donfrancesco C, Ippolito R, Lo Noce C, et al. (2013) Excess dietary sodium and inadequate potassium intake in Italy: results of the MINISAL study. Nutr Metab Cardiovasc Dis $\mathbf{2 3}$, 850-856.

21. Erdem Y, Arici M, Altun B, et al. (2010) The relationship between hypertension and salt intake in Turkish population: SALTURK study. Blood Press 19, 313-318.

22. Vertnik L, Vegnuti M, Ribic CH, et al. (2010) Salt intake of the Slovene population assessed by $24 \mathrm{~h}$ urinary sodium excretion. Public Health Nutr 13, 1803-1809.

23. Rhee MY, Shin SJ, Park SH, et al. (2013) Sodium intake of a city population in Korea estimated by 24 -h urine collection method. Eur J Clin Nutr 67, 875-880.

24. Polónia J (2006) Estimation of salt intake by urinary sodium excretion in a Portuguese adult population and its relationship to arterial stiffness. Rev Port Cardiol 25, 801-817.

25. Land M-A, Jeffery P, Webster J, et al. (2014) Protocol for the implementation and evaluation of a community-based intervention seeking to reduce dietary salt intake in Lithgow, Australia. BMC Public Health 14, 357.

26. Kamso S, Rumawas JSP, Lukito W, et al. (2007) Determinants of blood pressure among Indonesian elderly individuals who are of normal and over-weight: a cross sectional study in an urban population. Asia Pac J Clin Nutr 16, 546-553.

27. Mustafa A, Muslimatun S, Untoro J, et al. (2006) Determination of discretionary salt intake in an iodine deficient area of East Java-Indonesia using three different methods. Asia Pac J Clin Nutr 15, 362-367.

28. Farapti F, Fatimah AD, Astutik E, et al. (2020) Awareness of salt intake among community-dwelling elderly at coastal area: the role of public health access program. J Nutr Metab 2020, 8793869.

29. Sasaki S, Yanagibori R \& Amano K (1998) Self-administered diet history questionnaire developed for health education: a relative validation of the test-version by comparison with 3-day diet record in women. J Epidemiol 8, 203-215.

30. Brown IJ, Dyer AR, Chan Q, et al. (2013) Estimating 24-hour urinary sodium excretion from casual urinary sodium concentrations in western populations. Am J Epidemiol 177, 1180-1192.

31. Mente A, Dagenais G, Wielgosz A, et al. (2016) Assessment of dietary sodium and potassium in Canadians using 24-hour urinary collection. Can J Cardiol 32, 319-326.

32. Chen SL, Dahl C, Meyer HE, et al. (2018) Estimation of salt intake assessed by 24-hour urinary sodium excretion among Somali adults in Oslo, Norway. Nutrients 10, 900.

33. Holbrook JT (1984) Sodium and potassium intake and balance in adults consuming self-selected diets. Am J Clin Nutr $\mathbf{4 0}$, 786-793.

34. Elliott P \& Brown I (2007) Sodium Intakes Around the World. Geneva: WHO Press.

35. East Java Provincial Health Office (2019) Health Profile of East Java 2018. Dinas Kesehat. Provinsi Jawa Timur (in Indonesian). Surabay: East Java Provincial Health Office.

36. Ministry of Health of the Republic of Indonesia (2018) Main Results of Riskesdas 2018 (in Indonesian). Jakarta: Ministry of Health of the Republic of Indonesia.

37. President of the Republic of Indonesia (1998) The law of Republic of Indonesia about welfare of older adult. Pres. Decree, 1-8. Indonesia (in Indonesian). www.bphn.go.id (accessed May 2018).

38. WHO/PAHO Regional Expert Group for Cardiovascular Disease (2010) Protocol for Population Level Sodium Determination in 24-hour Urine Samples. Washington, DC: WHO/PAHO. 
39. World Health Organization (2017) WHO STEPS Instrument Question-by-Question Guide. WHO Website. http://www.who. int/ncds/surveillance/steps/en/ (accessed February 2018).

40. Mahony FI \& Barthel D (1965) Functional evaluation: the Barthel Index. Md State Med J 14, 56-61.

41. Borson S (2000) Mini-Cog Instructions for Administration \& Scoring. Mini-CogTM @ , 1-2. https://mini-cog.com/ (accessed January 2018).

42. Hagströmer M, Oja P \& Sjöström M (2006) The International Physical Activity Questionnaire (IPAQ): a study of concurrent and construct validity. Public Health Nutr 9, 755-762.

43. Ainsworth BE, Haskell WL, Herrmann SD, et al. (2011) 2011 Compendium of physical activities: a second update of codes and MET values. Med Sci Sports Exerc 43, 1575-1581.

44. Craig CL, Marshall AL, Sjöström M, et al. (2003) International physical activity questionnaire: 12 -country reliability and validity. Med Sci Sports Exerc 35, 1381-1395.

45. Subar AF, Midthune D, Tasevska N, et al. (2013) Checking for completeness of 24-h urine collection using para-amino benzoic acid not necessary in the observing protein and energy nutrition study. Eur J Clin Nutr 67, 863-867.

46. Reese JB, Bober SL, Daly MB, et al. (2003) INTERMAP: background, aims, design, methods, and descriptive statistics (nondietary). J Hum Hypertens 17, 591-608.

47. Rose G \& Stamler J (1989) The INTERSALT study: background, methods and main results. INTERSALT Co-operative Research Group. J Hum Hypertens 3, 283-288.

48. Murakami K, Sasaki S, Takahashi Y, et al. (2008) Sensitivity and specificity of published strategies using urinary creatinine to identify incomplete 24-h urine collection. Nutrition 24, 16-22.

49. Drawz PE, Abdalla M \& Rahman M (2012) Blood pressure measurement: clinic, home, ambulatory, and beyond. Am J Kidney Dis 60, 449-462.

50. Pickering TG (2002) Principles and techniques of blood pressure measurement. Cardiol Clin 20, 207-223.

51. Takahashi H, Yokoi T \& Yoshika M (2013) Validation of the Omron HEM-7201 upper arm blood pressure monitor, for self-measurement in a high-altitude environment, according to the European Society of Hypertension International Protocol revision 2010. J Hum Hypertens 27, 487-491.

52. British and Irish Hypertension Society (2017) Blood pressure monitors. https://bihsoc.org/bp-monitors/ (accessed May 2018).

53. British and Irish Hypertension Society (2017) Statement on the diagnosis of hypertension in obese patients with a large or very large arm circumference. https://bihsoc.org/wp-content/uploads/ 2017/11/Statement-on-diagnosis-of-hypertension-in-obesepatients-Nov-2017.pdf (accessed May 2018).

54. Knuiman J, Hautvast J, Van der Heyden L, et al. (1986) A multicentre study on completeness of urine collection in 11 European centres. I. Some problems with the use of creatinine and 4-aminobenzoic acid as markers of the completeness of collection. Hum Nutr Clin Nutr 40, 229-237.

55. John KA, Cogswell ME, Campbell NR, et al. (2016) Accuracy and usefulness of select methods for assessing complete collection of 24-hour urine: a systematic review. J Clin Hypertens $\mathbf{1 8}$ 456-467.

56. Fujiwara A, Asakura K, Uechi K, et al. (2016) Dietary patterns extracted from the current Japanese diet and their associations with sodium and potassium intakes estimated by repeated $24 \mathrm{~h}$ urine collection. Public Health Nutr 19, 2580-2591.

57. Northstone K (2012) Dietary patterns: the importance of sex differences. Br J Nutr 108, 393-394.

58. Joossens JV, Geboers J, Backer GG, et al. (1984) Monitoring salt intake of the population: methodological considerations.
In Surveillance of the Dietary Habits of the Population with Regard to Cardiovascular Diseases EURO-NUT Rep. 2, pp. 61-73 [GG Backer, HT Pedoe and P Ducimetiere, editors]. Wageningen: Wiley.

59. Dodd KW, Guenther PM, Freedman LS, et al. (2006) Statistical methods for estimating usual intake of nutrients and foods: a review of the theory. I Am Diet Assoc 106, 1640-1650.

60. Yokoyama T (2013) Theory and application of statistical methods to estimate the distribution of usual intakes of a nutrient in a population: for the appropriate use of dietary reference intakes. Japan J Nutr Diet 71, 7-14.

61. Nusser SM, Carriquiry AL, Dodd KW, et al. (1996) A semiparametric transformation approach to estimating usual daily intake distributions. J Am Stat Assoc 91, 1440-1449.

62. Ministry of Health of the Republic of Indonesia (2014) Guidelines for balanced nutrition of Indonesia. Ministry of Health of the Republic of Indonesia, 1-96. Jakarta, Indonesia (in Indonesian). https://kesmas.kemkes.go.id/perpu/konten/ permenkes/pmk-no.-41-ttg-pedoman-gizi-seimbang (accessed December 2019).

63. World Health Organization (2012) Guideline: Sodium Intake for Adults and Children. Geneva: WHO Press.

64. World Health Organization (2012) Guideline: Potassium Intake for Adults and Children. Geneva: WHO Press.

65. Willett W (2013) Nutritional Epidemiology. New York: Oxford University Press.

66. Chang Y, Guo X, Guo L, et al. (2016) Comprehensive comparison between empty nest and non-empty nest elderly: a crosssectional study among rural populations in northeast China. Int IEnviron Res Public Health 13, 857.

67. Xu J, Wang M, Chen Y, et al. (2014) Estimation of salt intake by 24-hour urinary sodium excretion: a cross-sectional study in Yantai, China. BMC Public Health 14, 136.

68. Uechi K, Asakura K, Masayasu S, et al. (2017) Within-country variation of salt intake assessed via urinary excretion in Japan: a multilevel analysis in all 47 prefectures. Hypertens Res 40, 598-605.

69. Noh H-M, Park S-Y, Lee H-S, et al. (2015) Association between high blood pressure and intakes of sodium and potassium among Korean adults: Korean National Health and Nutrition Examination Survey, 2007-2012. J Acad Nutr Diet $115,1950-1957$.

70. Indonesia P (2018) Indonesian Food Composition Table 2017 (in Indonesian). Jakarta: Ministry of Health of the Republic of Indonesia.

71. Pangestu AD (2019) Association of sodium and potassium intake, nutritional status, and physical activity with blood pressure in diabetes mellitus patients in Pesanggrahan District Health Center. ARGIPA (Arsip Gizi dan Pangan) 4, 54-64.

72. Ortega RM, Requejo AM, Andrés P, et al. (1995) Relationship between diet composition and body mass index in a group of Spanish adolescents. Br J Nutr 74, 765-73.

73. Yulia KH \& Fahmida U (2016) Dietary patterns of obese and normal-weight women of reproductive age in urban slum areas in Central Jakarta. Br J Nutr 116, 549-556.

74. Schulze MB, Hoffmann K, Kroke A, et al. (2001) Dietary patterns and their association with food and nutrient intake in the European Prospective Investigation into Cancer and Nutrition (EPIC)-Potsdam study. Br J Nutr 85, 363-373.

75. Gibson S \& Ashwell M (2011) Dietary patterns among British adults: compatibility with dietary guidelines for salt/ sodium, fat, saturated fat and sugars. Public Health Nutr 14, 1323-1336. 
76. Betancourt-Nuñez A, Márquez-Sandoval F, González-Zapata LI, et al. (2018) Unhealthy dietary patterns among healthcare professionals and students in Mexico. BMC Public Health 18 1246.

77. Ranilović J \& Colić Barić I (2011) Differences between younger and older populations in nutrition label reading habits. Br Food J 113, 109-121.
78. Mahendradhata $\mathrm{Y}$, Trisnantoro L, Listyadewi S, et al. (2017) The Republic of Indonesia Health System Review. New Delhi: WHO.

79. Rodrigues SL, Souza Júnior PR, Pimentel EB, et al. (2015) Relationship between salt consumption measured by 24-h urine collection and blood pressure in the adult population of Vitória (Brazil). Braz J Med Biol Res 48, 728-735. 